Article

\title{
Development of a Novel Cu(II) Complex Modified Electrode and a Portable Electrochemical Analyzer for the Determination of Dissolved Oxygen (DO) in Water
}

\author{
Salvatore Gianluca Leonardi ${ }^{1}$, Maryam Bonyani ${ }^{1,2}{ }^{,}$Kaushik Ghosh ${ }^{3}$, Ashish K. Dhara ${ }^{3}$, \\ Luca Lombardo ${ }^{1}$, Nicola Donato ${ }^{1}$ and Giovanni Neri ${ }^{1, *}$ \\ 1 Department of Engineering, University of Messina, C.da di Dio, 98166 Messina, Italy; \\ leonardis@unime.it (S.G.L.); maryam.bonyani@gmail.com (M.B.); eeeluca.rol@gmail.com (L.L.); \\ ndonato@unime.it (N.D.) \\ 2 Department of Materials Science and Engineering, Shiraz University, 85115-71946 Shiraz, Iran \\ 3 Department of Chemistry, Indian Institute of Technology, Roorkee, Roorkee 247 667, Uttarakhand, India; \\ ghoshfcy@iitr.ernet.in (K.G.); akdhara.iitr@gmail.com (A.K.D.) \\ * Correspondence: gneri@unime.it; Tel.: +39-90-397-7297; Fax: +39-90-397-7464
}

Academic Editor: Igor Medintz

Received: 19 January 2016; Accepted: 6 April 2016; Published: 21 April 2016

\begin{abstract}
The development of an electrochemical dissolved oxygen (DO) sensor based on a novel $\mathrm{Cu}(\mathrm{II})$ complex-modified screen printed carbon electrode is reported. The voltammetric behavior of the modified electrode was investigated at different scan rates and oxygen concentrations in PBS $(\mathrm{pH}=7)$. An increase of cathodic current (at about $-0.4 v s$. Ag/ $\mathrm{AgCl}$ ) with the addition of oxygen was observed. The modified $\mathrm{Cu}$ (II) complex electrode was demonstrated for the determination of DO in water using chronoamperometry. A small size and low power consumption home-made portable electrochemical analyzer based on custom electronics for sensor interfacing and operating in voltammetry and amperometry modes has been also designed and fabricated. Its performances in the monitoring of DO in water were compared with a commercial one.
\end{abstract}

Keywords: oxygen sensor; portable electrochemical analyzer; metal complex

\section{Introduction}

Dissolved oxygen (DO) is an essential indicator in biochemical processes. For example, the dissolved oxygen concentration is one of the main parameters to assess the quality of water for life of humans and animals in aquatic environments. Oxygen is indeed necessary to nearly all forms of life and water systems require an adequate oxygen level in order to allow aerobic life forms to develop [1].

Dissolved oxygen sensing in water is a well-established technology with many commercially available sensors (e.g., electrochemical sensors based on Clark electrodes and luminescence sensors). Besides this, research activity for proposing new materials for fabricating more affordable DO oxygen sensors is still very active. In recent years, metal complexes based on transition metals such as Ru and Os have become an important class of sensor materials for detecting dissolved $\mathrm{O}_{2}$ by use of solid-state fluorescence-based sensors [2]. However, metal complexes based on Ru and Os are expensive, then cheaper devices are desirable for practical applications. On the basis of their simple functioning and low cost, electrochemical devices have been used as transducers for dissolved oxygen sensing [3]. In this regard, the development of electrochemical devices for dissolved oxygen sensing based on transition metal complex is strongly encouraged because, compared to simple organic or inorganic materials, they offer a larger selection of molecular structures, the possibility of high environmental stability and a variety of electronic properties due to the coordinated metal center. 
Many metal complexes, based on $\mathrm{Co}, \mathrm{Ni}$, and $\mathrm{Cu}$ complexes, have been investigated for oxygen electroreduction [4-6]. Electrocatalytic reduction of $\mathrm{O}_{2}$ mainly depends of the metal center, however the electron withdrawing or donating nature of different ligands also contributes to this step. Therefore, the search for new complexes of the above metals with suitable ligands for their use in electrochemical sensors for DO detection is of great interest from scientific and applicative points of view.

Based on our previous experience about metal complexes as sensing elements for electrochemical sensors [7], we focused our attention on a novel $\mathrm{Cu}$ (II) complex as material for $\mathrm{O}_{2}$ reduction. The mononuclear copper(II) complex here proposed, [Cu(Phimp)(bipy) $\left.\left(\mathrm{ClO}_{4}\right)\right](\mathrm{I})$, comprises bipy(2,2'-bipyridine) and Phimp(1-phenyl-1-(pyridin-2-yl)-2-(pyridin-2-ylmethylene) hydrazine) as bi- and tri-dentate ligand, respectively:

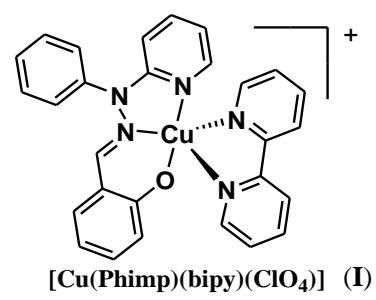

Copper complexes have recently attracted increasing attention as $\mathrm{O}_{2}$ reduction electrocatalysts $[8,9]$. Results clearly demonstrate electrocatalytic $\mathrm{O}_{2}$ reduction coupled with $\mathrm{Cu}(\mathrm{II}) / \mathrm{Cu}(\mathrm{I})$ conversion in aqueous solutions. Gewirth et al. recently reported that several $\mathrm{Cu}$ (II)-complexes adsorbed on a carbon black electrode can catalyze the electrocatalytic electron reduction of $\mathrm{O}_{2}$ [10]. Sousa et al. evaluated the electrochemical response and the stability of a $\left[\mathrm{Cu}_{4}(\text { apyhist })_{4}\right]^{4+}$ complex (apyhist $=2-(1 H$-imidazol-4-yl)- $N-(1-($ pyridin-2-yl)ethylidene)ethanamine) for the fabrication of a novel biomimetic oxygen sensor [11].

To the best of our knowledge, there is no report about complex (I) for oxygen electro-reduction. To investigate the electrochemical properties, the complex was deposited on a screen printed carbon electrode (SPCE), and used for the monitoring of DO in aqueous solution by means of cyclic voltammetry and chronoamperometric measurements. The development of a disposable electrode in the form of a sensing strip is more practical with regard to the demand of actual application to measure dissolved oxygen in various biomedical and environmental applications $[12,13]$. Further, due to the low toxicity, low cost, and availability of copper compared to the noble metals, the developed electrode will have a potential towards mass production for broad applications.

The main objective of our work is to develop a complete sensing platform for real time monitoring of the DO concentration in aqueous media as part of an effort to monitor water quality $[14,15]$. In such a context, commercial systems include expensive equipment, therefore the employment of home-made and low cost portable measurement systems, where system modularity for application adaptability is a primary design consideration, can be important to spread the number of applications. Thus, it is essential to design a low-cost instrument based on custom electronics that provide the capability of performing measurement in voltammetry, amperometry, and potentiometry modes in real time. The system architecture, modular packaging, and interface electronics of the designed and fabricated is here presented and its characteristics are compared with that of a commercial one for real time monitoring of DO in water.

\section{Experimental Section}

\subsection{Synthesis of $[\mathrm{Cu}$ (II Phimp)(bipy)]ClO 4 Complex (I)}

Complex (I) was synthesized as follows: first, ligand PhimpH (0.1445 g, $0.5 \mathrm{mmol})$ was dissolved in $5 \mathrm{~mL}$ of methanol, then a methanolic solution of copper(II) perchlorate hexahydrate $(0.185 \mathrm{~g}$, $0.5 \mathrm{mmol}$ ) was added to the ligand solution. The complex (I) was formed by the addition of 
a methanolic solution of 2,2'-bipyridine $(0.078 \mathrm{~g}, 0.5 \mathrm{mmol})$ to the above solution. A schematic drawing of the complex formation is reported in Scheme 1:

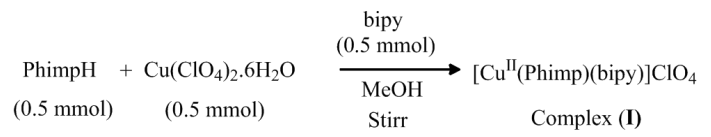

Scheme 1. Schematic drawing of the complex formation.

The elemental and chemical characterization of the product obtained has given the following results. Elemental Analysis: Calc. for $\mathrm{C}_{28} \mathrm{H}_{22} \mathrm{ClCuN}_{5} \mathrm{O}_{5}$. C, 55.36; H, 3.65; $\mathrm{Cl}, 5.84 ; \mathrm{Cu}, 10.46 ; \mathrm{N}, 11.53$; $\mathrm{O}, 13.17$. Found: $\mathrm{C}, 55.82 ; \mathrm{H}, 4.07 ; \mathrm{Cl}, 5.01 ; \mathrm{Cu}, 10.88 ; \mathrm{N}, 10.95 ; \mathrm{O}, 14.23$. IR $\left(\mathrm{KBr}\right.$ pellets, $\left.\mathrm{cm}^{-1}\right): v(\mathrm{C}=\mathrm{N})$, 1607. UV-vis (Acetonitrile) $\lambda_{\max }(\mathrm{nm})\left[\varepsilon\left(\mathrm{M}^{-1} \cdot \mathrm{cm}^{-1}\right)\right]: 226$ (49800), 410 (11320).

\subsection{Sensor Fabrication}

The sensor was fabricated by using a commercial screen printed three-electrode strip (Dropsens C110). It consists of a ceramic planar support with a carbon working electrode $4 \mathrm{~mm}$ in diameter, a carbon counter electrode and a silver pseudo-reference electrode.

A dense solution of active material was obtained dispersing $5 \mathrm{mg}$ of $\mathrm{Cu}$ (II)-complex in $0.1 \mathrm{~mL}$ of ethanol, then the working electrode was modified by casting $5 \mu \mathrm{L}$ of the above solution onto its surface and allowed to dry at room temperature. The solubility of the synthesized copper complex in ethanol ensures a uniform dispersion onto the carbon electrode and an excellent adhesion after the solvent evaporation. Furthermore, the poor water solubility ensures a good stability of the working electrode during its use.

\subsection{Electrochemical Analyzers}

Electrochemical measurements were performed by means of a commercial Dropsens $\mu$ Stat 400 potentiostat and a home-made analyzer. The home-made analyzer is based on the AVR 8/16 bits ATXMEGA128A3U microcontroller, manufactured by ATMEL Corporation. The chip features a rich set of peripherals, among them there are a 12-bit 2 MSPS multi-channel Analog-to-Digital Converter and a 12-bit dual Digital-to-Analog Converter that are used in data acquisition. A Power Supply Management Circuit allows high-efficiency, ultra-low power consumption, and the capability to shut-down the analog sensor front-end for achieving longer autonomy also with small-capacity batteries. The measurement data can be transmitted through the USB 2.0 interface, recorded, and visualized in real time, by using dedicated software written in Python. The firmware system can be programmed in order to periodically perform measurements in stand-alone mode, and optionally to store the data on an internal non-volatile memory.

\subsection{Electrochemical Tests}

Electrochemical tests were carried out in a three-electrode mode using the same counter and reference electrodes of the screen printed sensor. More detailed information can be found in a previous paper [16]. The dissolved oxygen (DO) measurements were carried out in $0.1 \mathrm{M}$ PBS solution ( $\mathrm{pH} 7$ ). DO level was controlled saturating the electrolyte solution by bubbling $\mathrm{N}_{2} / \mathrm{O}_{2}$ gas mixtures at different partial pressure. Cyclic voltammetry was performed in the potential range from -1 to $1 \mathrm{~V}$ at different scan rate in both nitrogen- and oxygen-saturated solution. Cyclic voltammograms were recorders for the same sensor and at the same conditions, by means of both commercial and home-made analyzers. The recorded data were used to evaluate any discrepancies in the acquired signal between the two devices.

Chrono-amperometric experiments were carried out, first in $\mathrm{O}_{2}$ saturated solution in order to identify the optimal potential, then recording the current signal at fixed potential during cyclic saturation and purging of the solution with $\mathrm{O}_{2}$ and $\mathrm{N}_{2}$. 


\section{Results and Discussion}

\subsection{Electrochemical Characterization of Modified Electrode}

First, an electrochemical characterization of the synthesized copper complex (I) was undertaken. Reversible redox cathodic peaks were observed in PBS in the absence of oxygen and attributed to the reduction of $\mathrm{Cu}^{2+}$ to form $\mathrm{Cu}^{+}$and $\mathrm{Cu}^{0}$, whereas the anodic peak was ascribed to the oxidation of $\mathrm{Cu}^{+}$to $\mathrm{Cu}^{2+}$ [16]. In the presence of oxygen molecules, the reduction current was remarkably increased. Meanwhile, the oxidation peak there could not be observed anymore, suggesting that there is a catalytic reaction which catalyze, in the first step, the reduction of the complex (I), here indicated, for simplicity, as $\mathrm{Cu}(\mathrm{II})-\mathrm{L}(\mathrm{L}=$ ligands):

$$
\begin{aligned}
& \mathrm{Cu}(\mathrm{II})-\mathrm{L}+\mathrm{e}^{-} \rightarrow \mathrm{Cu}(\mathrm{I})-\mathrm{L} \\
& \mathrm{Cu}(\mathrm{I})-\mathrm{L}+\mathrm{O}_{2} \rightarrow \mathrm{Cu}(\mathrm{II})-\mathrm{L}
\end{aligned}
$$

These observations also strongly suggest that copper complex (I) may have promising sensing capabilities for oxygen sensing. Furthermore, due to the insolubility of $\left[\mathrm{Cu}(\mathrm{Phimp})(\mathrm{bipy})\left(\mathrm{ClO}_{4}\right)\right]$ complex in aqueous medium the electrode has high stability, which is a critical factor for the development of oxygen sensors for practical use.

In view of the above results, we decided to investigate the possible use of this modified electrode as a sensor for dissolved $\mathrm{O}_{2}$ in aqueous solution. To study the electrocatalytic behavior of the $\mathrm{Cu}$-complex based electrode towards oxygen reduction, cyclic voltammetry was performed in $0.1 \mathrm{M}$ PBS saturated with oxygen and purged by it. The cyclic voltammograms obtained in presence of different oxygen concentration and recorded in the potential range -1 to $1 \mathrm{~V}$ at a scan rate of $50 \mathrm{mV} / \mathrm{s}$, are displayed in Figure 1a. As stated above, in the absence of oxygen, some anodic and cathodic peaks are observable in the range -0.1 to $0.25 \mathrm{~V}$ due to reversible oxidation and reduction processes of copper. In presence of $\mathrm{DO}$ in the analyte solution, a marked reduction peak with a maximum at about $-0.4 \mathrm{~V}$ was observed. Moreover, increasing the concentration of oxygen a corresponding increasing of the cathodic peak current was also observed. The typical current-oxygen concentration behavior, obtained from cathodic peak at $-0.4 \mathrm{~V}$, is shown in Figure $1 \mathrm{~b}$. A good linear trend in the range from 0 to $42 \mathrm{mg} / \mathrm{L} \mathrm{DO}$ has been obtained with equation: $\mathrm{i}_{\mathrm{p}}(\mu \mathrm{A})=2.36 \mathrm{O}_{2}(\mathrm{mg} / \mathrm{L})+49\left(R^{2}=0.997\right)$.
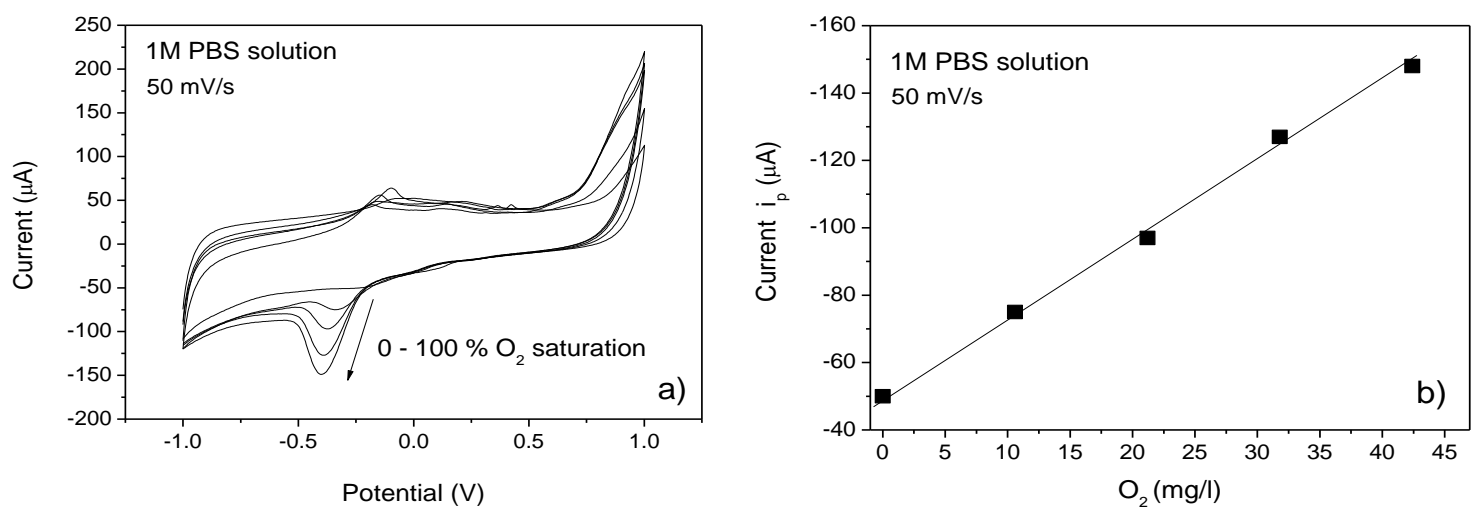

Figure 1. (a) Cyclic voltammograms obtained in presence of different oxygen concentration and recorded in the potential range from -1 to $1 \mathrm{~V}$ at a scan rate of $50 \mathrm{mV} / \mathrm{s}$; (b) current-oxygen concentration behavior, obtained from cathodic peak at $-0.4 \mathrm{~V}$.

The effect of scan rate $(10-100 \mathrm{mV} / \mathrm{s})$ on cyclic voltammetry response was investigated in presence of oxygen saturated solution (Figure $2 \mathrm{a})$. The reduction peak increase increasing the scan rate (Figure $2 \mathrm{~b})$ showing a linear correlation with equation $\mathrm{i}_{\mathrm{p}}(\mu \mathrm{A})=1.51 v(\mathrm{mV} / \mathrm{s})+49\left(R^{2}=0.996\right)$, A slight 
shift towards higher negative potential was also observed. This behavior is typical of non-reversible electrochemical adsorption processes.
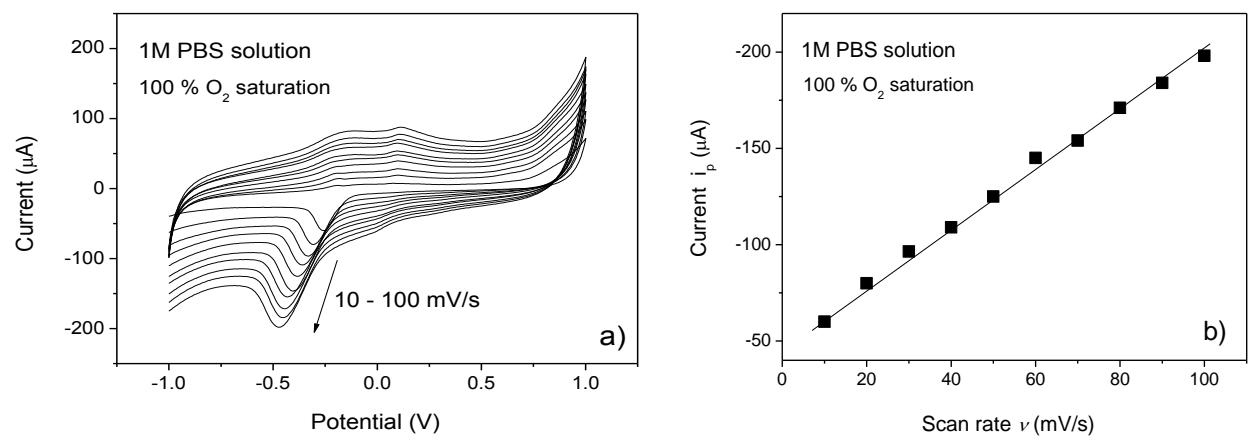

Figure 2. (a) Effect of scan rate $(10-100 \mathrm{mV} / \mathrm{s})$ on cyclic voltammetry response in an oxygen saturated solution; (b) correlation between the reduction peak and the scan rate.

From these data, it can be deduced that $\mathrm{Cu}(\mathrm{II})$-complex (I) adsorbed on SPCE electrode catalyzes the reduction of $\mathrm{O}_{2}$, likely through a stepwise 4-electron process. However, there is no evidence that the direct 4-electron reduction of $\mathrm{O}_{2}$ by $\mathrm{Cu}$ (II)-complex (I) does not occur, and a further investigation is needed to clarify the pathway of electrochemical $\mathrm{O}_{2}$ reduction by this modified electrode.

\subsection{Home-Made Electronic Readout System}

A portable analyzer for electrochemical sensors has been also designed and developed. The developed analog front-end allows the interfacing with electrochemical sensors, providing a wide bias range spanning from $-1.0 \mathrm{~V}$ to $+1.0 \mathrm{~V}$ with a resolution of about $1 \mathrm{mV}$ and a current sensing range going from $10 \mathrm{nA}$ to $8 \mathrm{~mA}$, with five range options that can be selected by the CPU firmware. The block diagram of the electronic system is shown in Figure 3.

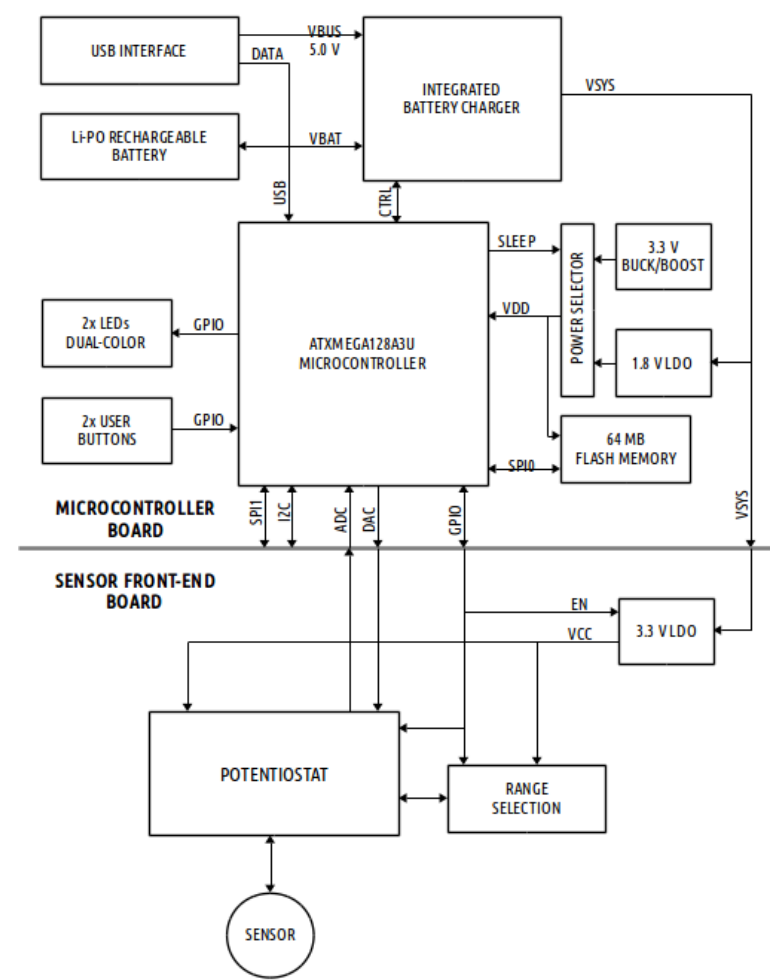

Figure 3. The block diagram of the developed electronic system. 
The system is implemented in two distinct boards: the Microcontroller Board and the Sensor Front-End Board. The Microcontroller Board features the ATXMEGA128A3U microcontroller circuitry, the USB Interface used to connect the measurement system with a PC for control and data exchanging, the power supply system with two regulators, and a Li-PO battery charger circuit. The system can be powered alternatively from the USB or the battery. A PDI Interface Connector is also provided to update the microcontroller firmware. The Sensor Front-End Board is connected using a standard connector with a pitch of $1.27 \mathrm{~mm}$. Two dual-color LEDs and two user buttons are available respectively for status information and user interaction. The performance of the home-made manufactured portable analyzer was tested by comparison with the commercial one (Figure $4 a, b$ ).
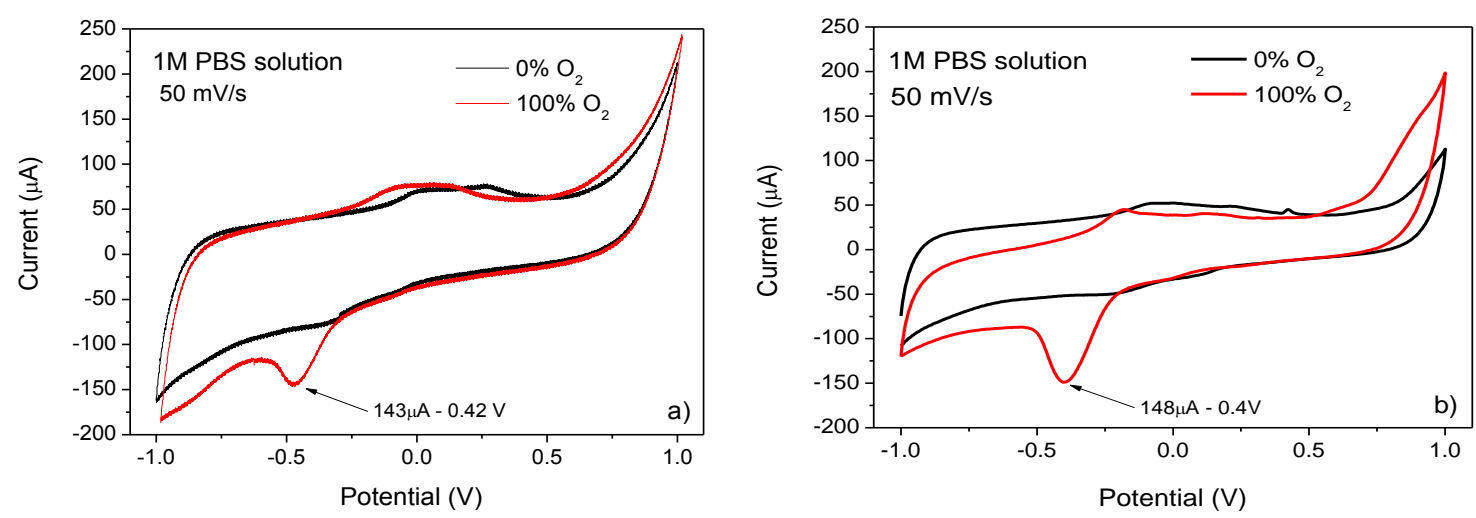

Figure 4. Cyclic voltammograms obtained in presence of different oxygen concentration and recorded in the potential range from -1 to $1 \mathrm{~V}$ at a scan rate of $50 \mathrm{mV} / \mathrm{s}$ on: (a) home-made manufactured portable analyzer; (b) commercial one.

\subsection{Oxygen Monitoring in Water}

Amperometric measurements were performed in stirring solution during continues bubbling of $\mathrm{O}_{2} / \mathrm{N}_{2}$ gas mixture inside. First, we investigate the effect of applied potential at the working electrode of the sensor. In Figure 5a, the chrono-amperometric responses of the sensor obtained in $\mathrm{O}_{2}$ saturated solution at different applied potentials ranging from $-0.1 \mathrm{~V}$ to $-1 \mathrm{~V}$ are shown. The reduction process of oxygen occurs for potentials higher than $-0.2 \mathrm{~V}$ and reaches a limit current at about $-0.4 \mathrm{~V}$ (Figure $5 \mathrm{~b}$ ). Increasing the potential over this value has not produced a remarkable increase of reduction current. With above consideration, the constant potential of $-0.4 \mathrm{~V}$ was chosen as the optimal detection potential for the amperometric tests.
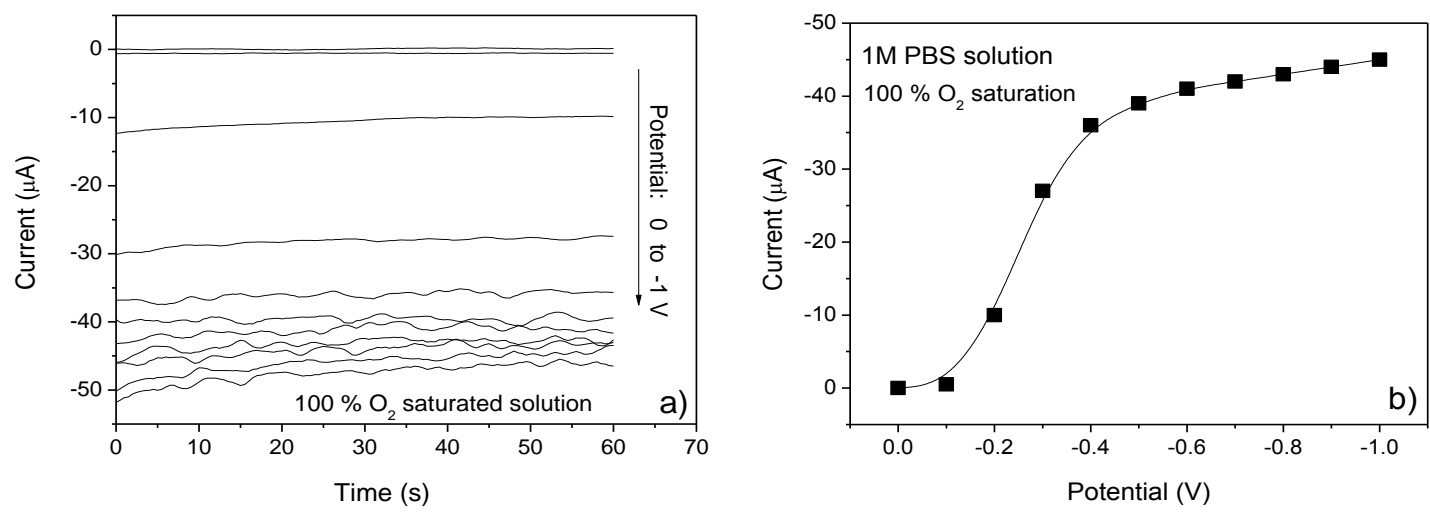

Figure 5. (a) Chrono-amperometric responses of the sensor obtained in $100 \% \mathrm{O}_{2}$ saturated solution at different applied potentials ranging from $-0.1 \mathrm{~V}$ to $-1 \mathrm{~V}$; (b) current-potential relationships. 
In Figure $6 \mathrm{a}$ is shown the chrono-amperometric test obtained at an applied potential of $-0.4 \mathrm{~V}$ during cycling saturation and purging of solution by oxygen at different partial pressure between $2 \%$ and $20 \%(\sim 2.1-8.5 \mathrm{mg} / \mathrm{L} \mathrm{DO})$. The sensor quickly follows the diffusion of oxygen in solution and completely recovers the baseline signal when the solution is de-aerated. The calibration curve obtained by plotting the measured current values versus different $\mathrm{DO}$ concentrations presents an excellent linear behavior with equation ip $(\mu \mathrm{A})=0.64 \mathrm{O}_{2}(\mathrm{mg} / \mathrm{L})+0.15\left(R^{2}=0.992\right)$. The average sensitivity was calculated to be $5.12 \mu \mathrm{A} / \mathrm{mg} \cdot \mathrm{L}^{-1} \cdot \mathrm{cm}^{-2}$.
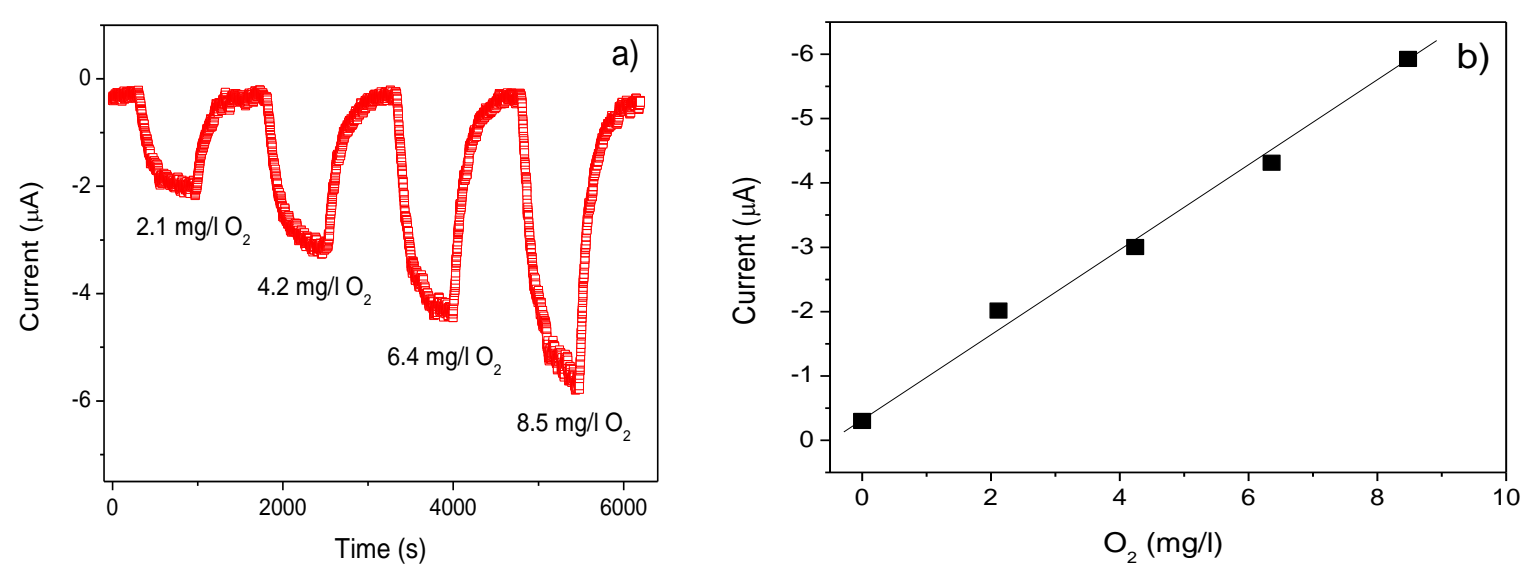

Figure 6. (a) Chrono-amperometric test obtained at an applied potential of $-0.4 \mathrm{~V}$ during cycling saturation and purging of solution by oxygen at different partial pressure between $5 \%$ and $20 \%$; (b) calibration curve of the sensor for different DO concentrations.

Table 1 shows a comparison of the performance of our sensor with that of other sensors based on $\mathrm{Cu}$ electrodes for monitoring of dissolved oxygen in water. 
Table 1. Comparison of the sensing characteristics of previous Cu-based dissolved oxygen sensors.

\begin{tabular}{|c|c|c|c|c|c|c|c|c|}
\hline Electrode & $\begin{array}{c}\text { Electrode Area } \\
\left(\mathrm{cm}^{2}\right)\end{array}$ & Technique & $\mathrm{pH}$ & $\begin{array}{c}\text { Potential } \\
\mathrm{Ag} / \mathrm{AgCl}(\mathrm{V})\end{array}$ & $\begin{array}{c}\text { Sensitivity } \\
{\left[\mu \mathrm{A} /\left(\mathrm{mg}^{-1} \mathrm{~L}^{-1}\right)\right]}\end{array}$ & $\begin{array}{c}\text { Sensitivity } \\
{\left[\mu \mathrm{A} /\left(\mathbf{m g} \cdot \mathbf{L}^{-1}\right) \mathbf{c m}^{-2}\right]}\end{array}$ & $\begin{array}{c}\text { Linear Range } \\
{\left[\mathrm{mg} \cdot \mathrm{L}^{-1}\right]}\end{array}$ & References \\
\hline $\begin{array}{l}\mathrm{Cu}(\mathrm{II}) \text { 4-imidazolyl ethylene } \\
\text { 2-amino-1-ethylpyridine-Nafion/GCE }\end{array}$ & 0.071 & Cyclic Voltammetry & 7 & -0.35 & 5.69 & 80.1 & $3-13$ & {$[11]$} \\
\hline $\begin{array}{l}\mathrm{Cu}(\mathrm{II}) \text { aminopropyl complex-cellulose } \\
\text { acetate/Pt disk }\end{array}$ & - & Cyclic Voltammetry & 7 & 0.15 & 96.64 & - & $1.9-12.1$ & [17] \\
\hline $\begin{array}{l}\mathrm{Cu}(\mathrm{II}) \text { complex 1-phenyltriazenido- } \\
\text { 2-phenyltriazene-benzene/Pt disk }\end{array}$ & - & Chronoamperometry & 7 & -0.25 & 1.05 & - & $1.1-5.2$ & [18] \\
\hline $\mathrm{Cu}$ layered/SPCE & 0.13 & $\begin{array}{l}\text { Photoelectrochemical } \\
\text { Chronoamperometry }\end{array}$ & 8 & -0.7 & 3.05 & 23.46 & $1-8$ & [19] \\
\hline $\mathrm{Pt}$ NPs/Cu needle & 0.0025 & Cyclic Voltammetry & 7 & -0.5 & 0.28 & 112 & $0.32-6.2$ & [20] \\
\hline $\mathrm{Cu}(\mathrm{II})(\mathrm{Phimp})(\mathrm{bipy})\left(\mathrm{ClO}_{4}\right) / \mathrm{SPCE}$ & 0.125 & $\begin{array}{l}\text { Cyclic Voltammetry } \\
\text { Chronoamperometry }\end{array}$ & $\begin{array}{l}7 \\
7\end{array}$ & $\begin{array}{l}-0.4 \\
-0.4\end{array}$ & $\begin{array}{l}2.36 \\
0.64\end{array}$ & $\begin{array}{l}18.8 \\
5.12\end{array}$ & $\begin{array}{c}0.42-42 \\
0.42-8\end{array}$ & This work \\
\hline
\end{tabular}


To the best of our knowledge, there is no report about electrodes modified with $\left[\mathrm{Cu}\right.$ (Phimp)(bipy) $\left.\left(\mathrm{ClO}_{4}\right)\right]$ complex for oxygen monitoring. The behavior reported for our sensor, measured in a wider linear range, extending practically from pure nitrogen to pure oxygen, is comparable with the performance of previous dissolved oxygen sensors based on other $\mathrm{Cu}$ (II) complexes. Further, it should be noted that the proposed screen printed sensor has a potential towards mass production larger than the previous sensors based on conventional electrochemical architecture.

\section{Conclusions}

Here, we have reported about the development of an oxygen sensor and a portable monitoring system for dissolved oxygen in water. The proposed sensor, based on a modified SPCE electrode with a $\mathrm{Cu}$ (II) complex sensing layer, showed a good response for dissolved oxygen at an applied potential of $-0.4 \mathrm{~V}$. The home-made analyzer, based on custom electronics, has shown performance similar to a commercial one.

Future activities are in progress in order to: (i) investigate the sensing mechanism and the effects of ligands by employing different substituents at the $\mathrm{Cu}$ center; (ii) extend the measurements to other analytes, e.g., nitrates and nitrites, for which specific sensors are under development and will be tested together with the proposed dissolved oxygen sensors for better assessing water quality.

In summary, the proposed system built and characterized in our laboratory presents an optimum solution for a comprehensive management of DO measurement in aqueous media and can be easily modified to be used with a wide variety of other sensing elements, achieving a wide scope of applications.

Author Contributions: All authors contributed equally to this work. K. Ghosh and A. K. Dhara, synthesized the complex. S. G. Leonardi and M. Bonyani performed the electrochemical measurements. L. Lombardo and N. Donato designed and fabricated the home-made electrochemical analyzer. G. Neri supervised and managed the paper.

Conflicts of Interest: The authors declare no conflict of interest.

\section{References}

1. Ansa-Asare, O.D.; Marr, I.L.; Cresser, M.S. Evaluation of modelled and measured patterns of dissolved oxygen in a freshwater lake as an indicator of the presence of biodegradable organic pollution. Water Res. 2000, 34, 1079. [CrossRef]

2. Xiong, X; Xiao, D.; Choi, M.F. Dissolved oxygen sensor based on fluorescence quenching of oxygen-sensitive ruthenium complex immobilized on silica-Ni-P composite coating. Sens. Actuators B: Chem. 2006, 117, 172-176.

3. Taillefert, M.; Luther, G.W.; Nuzzio, D.B. The application of electrochemical tools for in situ measurements in aquatic systems. Electroanalysis 2000, 12, 401-412. [CrossRef]

4. Asahi, M.; Yamazaki, S.; Itoh, S.; Ioroi, T. Electrochemical reduction of dioxygen by copper complexes with pyridylalkylamine ligands dissolved in aqueous buffer solution: The relationship between activity and redox potential. Dalton Trans. 2014, 43, 10705. [CrossRef] [PubMed]

5. Jiang, J.; Kucernak, A. Novel electrocatalyst for the oxygen reduction reaction in acidic media using electrochemically activated iron 2,6-bis(imino)-pyridyl. Electrochim. Acta 2002, 47, 1967-1973. [CrossRef]

6. Hermann, A.; Silva, L.S.; Peixoto, C.R.M.; de Oliveira, A.B.; Bordinhão, J.; Hörner, M. Electrochemical properties of $\mathrm{Cu}_{4}\left[\mathrm{PhN}_{3} \mathrm{C}_{6} \mathrm{H}_{4} \mathrm{~N}_{3}(\mathrm{H}) \mathrm{Ph}\right]_{4}(\mu-\mathrm{O})_{2}$, a tetranuclear copper(II) complex with 1-phenyltriazenido2-phenyltriazene-benzene as ligand. Eclét. Quim. 2008, 33, 43-46. [CrossRef]

7. Leonardi, S.G.; Aloisio, D.; Donato, N.; Rathi, S.; Ghosh, K.; Neri, G. Electrochemical sensing of ascorbic acid by a novel manganese(III) complex. Mater. Lett. 2014, 133, 232-235. [CrossRef]

8. Das, D.; Lee, Y.; Ohkubo, K.; Nam, W.; Karlin, K.D. Acid-induced mechanism change and overpotential decrease in dioxygen reduction catalysis with a dinuclear copper complex. J. Am. Chem. Soc. 2013, $135,4018$. [CrossRef] [PubMed]

9. Osako, T.; Ohkubo, K.; Taki, M.; Tachi, Y.; Fukuzumi, S.; Itoh, S. Oxidation mechanism of phenols by dicopper-dioxygen $\left(\mathrm{Cu}_{2} / \mathrm{O}_{2}\right)$ complexes. J. Am. Chem. Soc. 2003, 125, 11027. [CrossRef] [PubMed] 
10. Thorseth, M.A.; Letko, C.S.; Tse, E.C.M.; Rauchfuss, T.B.; Gewirth, A.A. Ligand effects on the overpotential for dioxygen reduction by tris(2-pyridylmethyl)amine derivatives. Inorg. Chem. 2013, 52, 628. [CrossRef] [PubMed]

11. Sousa, C.P.; Coutinho-Neto, M.D.; Liberato, M.S.; Kubota, L.T.; Alves, W.A. Self-assembly of peptide nanostructures onto an electrode surface for non-enzymatic oxygen sensing. J. Phys. Chem. C 2014, 119, 1038-1046. [CrossRef]

12. Lin, M.S.; Leu, H.J.; Lai, C.H. Method and Electrochemical Sensing Strip with Screen-Printed Three Electrodes for Determining Concentration of Dissolved Oxygen in a Solution. U.S. Patent 20,100,326,845, 30 December 2010.

13. Wang, Y.; Xu, H.; Zhang, J.; Li, G. Electrochemical sensors for clinic analysis. Sensors 2008, 8, $2043-2081$. [CrossRef]

14. Ramamoorthy, R.; Dutta, P.K.; Akbar, S.A. Oxygen sensors: Materials, methods, designs and applications. J. Mater. Sci. 2003, 38, 4271-4282. [CrossRef]

15. Mukhopadhyay, S.C.; Mason, A. Smart Sensors for Real-Time Water Quality Monitoring; Springer: Berlin, Germany, 2013.

16. Bonyani, M.; Mirzaei, A.; Leonardi, S.G.; Bonavita, A.; Neri, G. Electrochemical properties of Ag@iron oxide nanocomposite for application as nitrate sensor. Electroanalysis 2015, 27, 2654-2662. [CrossRef]

17. Lazarin, A.M.; Borgo, C.A.; Gushikem, Y. A platinum electrode coated with a copper(II) aminopropyl complex-cellulose acetate membrane and its use for dissolved oxygen reduction. J. Membr. Sci. 2003, 221, 175-184. [CrossRef]

18. Tu, Y. A sensitive dissolved oxygen sensor based on a charge-transfer complex modified electrode. Sens. Transducers 2006, 64, 483-489.

19. Zen, J.M.; Song, Y.S.; Chung, H.H.; Hsu, C.T.; Kumar, A.S. Photoelectrochemical oxygen sensor using copper-plated screen-printed carbon electrodes. Anal. Chem. 2002, 74, 6126-6130. [CrossRef] [PubMed]

20. Fang, Y.; Zhang, D.; Xia, Q.; Hong, S.; Xu, Y.; Guo, Y. Fabrication of a needle microsensor and its applications in the detection of dissolved oxygen. J. Sens. 2015, 2015, 408458. [CrossRef]

(C) 2016 by the authors; licensee MDPI, Basel, Switzerland. This article is an open access article distributed under the terms and conditions of the Creative Commons Attribution (CC-BY) license (http://creativecommons.org/licenses/by/4.0/). 